\title{
Use of contrast echocardiography in diagnosis of anomalous connection of right superior vena cava to left atrium
}

\author{
A TIMOTHY TRUMAN, P SYAMASUNDAR RAO, RAJU J KULANGARA \\ From the Section of Pediatric Cardiology, Department of Pediatrics, Medical College of Georgia, \\ Augusta, Georgia, USA.
}

SUMMARY A 4-month-old infant with cyanosis but without other abnormal cardiac findings is presented in whom the diagnosis of anomalous systemic venous connection to the left atrium was made by contrast echocardiography. The diagnosis was later confirmed by cardiac catheterisation and selective cineangiography. When saline was injected into a vein on the dorsum of each hand while echocardiographically recording the cardiac structures, the left atrium, left ventricle, and aorta were opacified without visualisation of the right ventricle. Similar study with injection into the right foot produced opacification of the right ventricle without visualisation of the left-sided structures. These data suggested normal drainage of the inferior vena cava with anomalous connection of the superior vena cava to the left atrium.

A review of the previously reported cases of anomalous connection of the right superior vena cava to the left atrium is presented together with the possible embryological origin of this anomaly.

Since the original description of Gramiak and Shah, ${ }^{1}$ contrast echocardiography has been used to validate echocardiographic identification of cardiovascular structures, ${ }^{23}$ to detect left-to-right or right-to-left shunts ${ }^{4-9}$ or valvar regurgitation, ${ }^{45}$ and to diagnose a variety of congenital heart defects. ${ }^{45-12}$ We have used this technique with peripheral vein saline injection $^{69}$ to diagnose a unique case of systemic venous connection to the left atrium which was later confirmed by cardiac catheterisation and selective cineangiography. The purpose of this report is to illustrate the usefulness of contrast echocardiography in the diagnosis of anomalous systemic venous connection to the left atrium and to present the details of this rare anomaly. Review of the previously reported cases of this anomaly and a hypothesis of its embryological development will also be presented.

\section{Case report}

A 4-month-old asymptomatic female infant, the product of a full-term normal pregnancy, labour, and delivery, was found to have moderate cyanosis by the paediatrician. After confirming low arterial $\mathrm{Po}_{2}$ (31 torr in room air) the infant was referred for further evaluation. Physical examination was completely normal with the exception of moderate central cyanosis. The electrocardiogram was normal. Chest $x$-ray films showed a prominent thymic shadow and questionable mildly decreased pulmonary vascular markings. Her haemoglobin was $13.6 \mathrm{~g} /$ $100 \mathrm{ml}$ and haematocrit 41 per cent. M-mode echocardiogram was interpreted as normal. Right radial artery $\mathrm{PO}_{2}$ was 32 torr in $\mathrm{FIO}_{2}$ of 0.21 and the acid base status was normal. These remained unchanged in $\mathrm{FIO}_{2}$ of 1.0 for 15 minutes.

Echocardiograms were performed by standard techniques using an Irex Continutrace echocardiograph with a $3.5 \mathrm{MHz}$ focused transducer. ${ }^{13}{ }^{14}$ With the patient in the supine position, the transducer was positioned along the left sternal border in the fourth intercostal space. Recordings of left ventricular cavity (with the right ventricle anterior to it) and aortic root (with the left atrium behind it and right ventricular outflow tract in front of it) were successively made while injecting 1.0 to $1.5 \mathrm{ml}$ normal saline through 25 gauge scalp vein needles inserted into veins of the right and left hands and right foot. These contrast echocardiograms were performed in duplicate. With injection into either hand, the left atrium and aorta were opacified without the appearance of contrast echoes in the right ventricular outflow tract (Fig. $1 \mathrm{~A}$ and $\mathrm{C}$ ). 


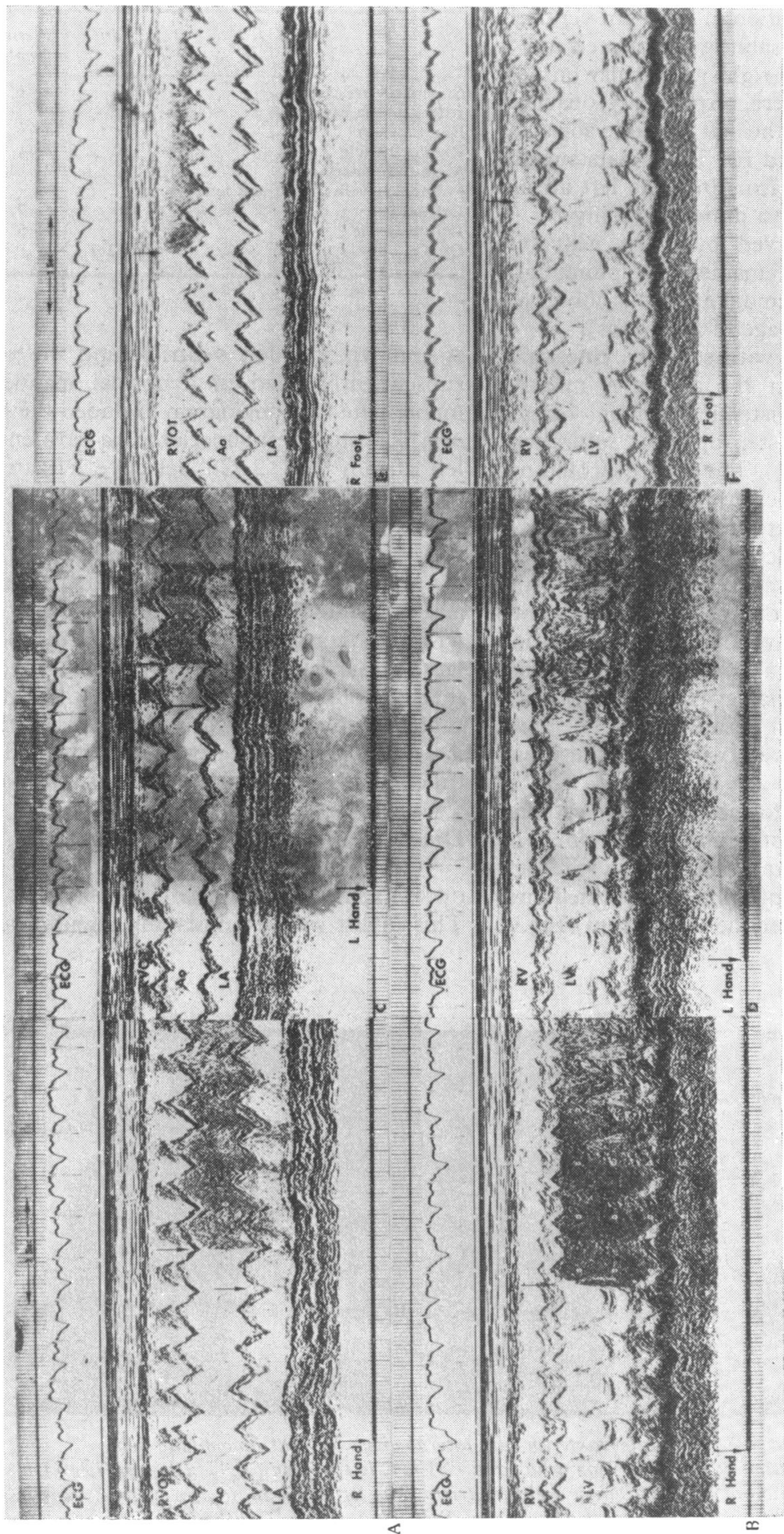

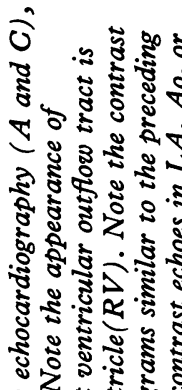
ชै ह จำ

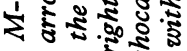
คे

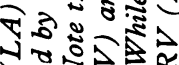

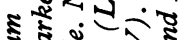
ำ

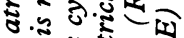
2.8.

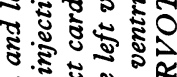

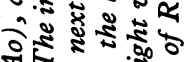

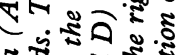

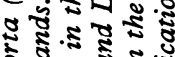

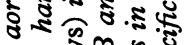

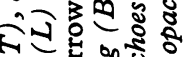

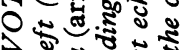

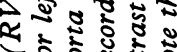
บิ

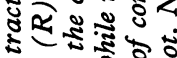
3.

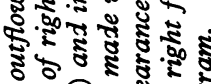
ธิ

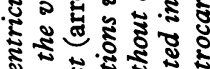
จั ज. ह 2 万. कृ ร.

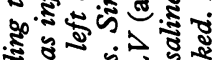

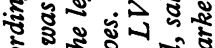

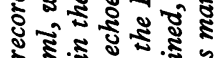
รั ₹ั

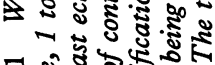

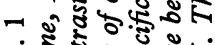

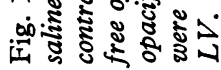

응

$\frac{c}{\frac{c}{0}}$

बำ

है

○

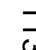

c.

כ

f

\%

光

음

\begin{tabular}{l} 
D \\
$\mathbb{D}$ \\
$\mathbb{D}$ \\
3 \\
$\bar{\Xi}$ \\
$\mathbb{1}$ \\
\hline 0 \\
0
\end{tabular}

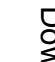

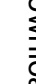

ำ

읔

三

궁

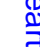

읔

ถิ่

오

글

N

음

స్తు

말

$\stackrel{0}{\mathbb{D}}$

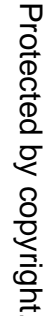


Similarly, the contrast echoes appeared in the left ventricle without opacification of the right ventricle (Fig. $1 \mathrm{~B}$ and D). When saline was injected into a vein of the right foot, the right ventricular outflow tract and right ventricle were, respectively, opacified without opacification of the left atrium, aorta, or left ventricle (Fig. $1 \mathrm{E}$ and $\mathrm{F}$ ). These data suggest venous drainage of both arms into the left atrium while the inferior vena cava drains normally.

The infant was observed over the next few months and, though she remained asymptomatic, a gradual increase in haemoglobin was observed ( $\mathrm{Hb} 15.0 \mathrm{~g} / 100 \mathrm{ml}$ at the age of 8 months).

Cardiac catheterisation with selective cineangiography was performed at the age of 8 months. There was minimal systemic venous oxygen desaturation without any step-up in $\mathrm{O}_{2}$ saturations in the right heart (Table 1). The catheter could not be advanced into the superior vena cava from the right atrium. The catheter could be advanced, however, though with difficulty, into the left atrium via a patent foramen ovale and from there into the superior vena cava and both right and left innominate veins. The pulmonary venous oxygen saturation was normal and there was a severe step-down in the $\mathrm{O}_{2}$ saturation at the left atrial level with the resultant moderate systemic arterial desaturation. The right and left heart pressures were within normal limits (Table 1).

An angiogram was performed with the catheter tip positioned in the right innominate vein. The right superior vena cava (into which the left innominate vein also emptied) was opacified first and was then seen to enter the left atrium (Fig. 2
Table 1 Cardiac catheterisation data

\begin{tabular}{|c|c|c|}
\hline Site & $\begin{array}{l}\mathrm{O}_{2} \text { saturation } \\
(\%)\end{array}$ & $\begin{array}{l}\text { Pressure } \\
(\mathrm{mmHg})\end{array}$ \\
\hline $\begin{array}{l}\text { Superior vena cava } \\
\text { Inferior vena cava } \\
\text { Right atrium } \\
\text { Right ventricle } \\
\text { Main pulmonary artery } \\
\text { Pulmonary veins (right and left) } \\
\text { Left atrium } \\
\text { Left ventricle } \\
\text { Qp:Qs }\end{array}$ & $\begin{array}{l}60 \\
62 \\
62 \\
60 \\
60 \\
98 \\
79 \\
79 \\
\\
\\
0 \cdot 5: 1 \cdot 0\end{array}$ & $\begin{array}{l}a=6, v=8, m=7 \\
\overline{a=4}, v=3, m=4 \\
23 / 4 \\
21 / 14, m=16 \\
\overline{a=7}, v=8, m=7 \\
75 / 6\end{array}$ \\
\hline
\end{tabular}

$A$ and B). The left ventricle and the aorta were subsequently filled in a normal manner. A left innominate vein angiogram excluded the possibility of a persistent left superior vena cava entering the left atrium (Fig. $2 \mathrm{C}$ ). Selective left atrial angiography showed retrograde opacification of the rightsided superior vena cava for a short distance but there was no evidence for a persistent left superior vena cava. Thus, the data from the catheterisation and angiography confirmed the diagnosis made with the contrast echocardiography. Because of lack of symptoms and only mild polycythaemia (haemoglbin of $15.0 \mathrm{~g} / 100 \mathrm{ml}$ at the time of the catheterisation) surgical correction of the defect is deferred for the present but is planned for some time in the future.

\section{Discussion}

CONTRAST ECHOCARDIOGRAPHY

This infant with cyanosis and significant systemic

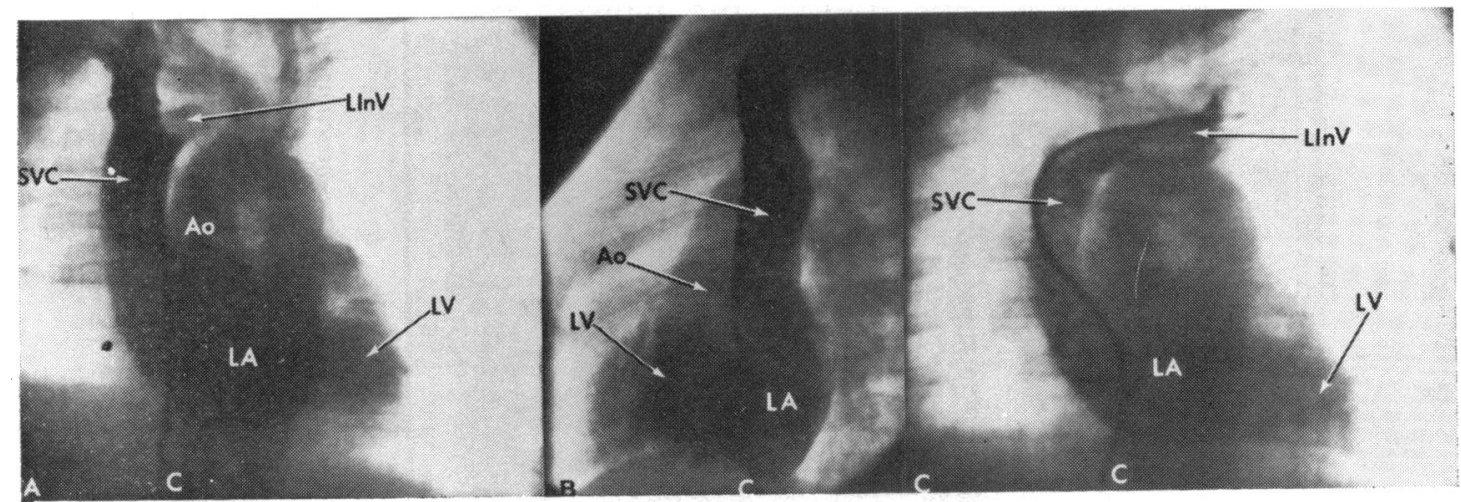

Fig. 2 Selected frames (A and B) from posteroanterior and lateral views of right innominate vein cineangiogram. Note opacification of right superior vena cava (SVC), left atrium (LA), left ventricle ( $L V)$, and aorta (Ao) without opacification of right atrium or right ventricle. The left innominate vein ( $L I n V)$ was faintly opacified. LInV angiographic frame (C) shows opacification of SVC, LA, and LV without opacification of right atrium or ventricle. There was no opacification of a left superior vena cava. $C$, catheter. 
arterial desaturation and no other abnormal cardiac findings presents an interesting differential diagnosis $^{15}$ which includes pulmonary arteriovenous fistula, pulmonary arterial connection to the left atrium, and anomalous systemic venous connection to the left atrium. We used the contrast echocardiographic technique to aid in this differential diagnosis. In patients with pulmonary arteriovenous fistula or pulmonary artery connection to the left atrium, one would expect appearance of contrast echoes in the right ventricle before being seen in the left atrium, left ventricle, or aorta. Furthermore, in these entities there is no anatomical basis for differential echo contrast opacification when saline was injected into the veins of the hands and foot. Contrast visualisation of the right ventricle and right ventricular outflow tract with injection into the foot in this infant suggested a normal venous drainage of the lower part of the body. Opacification of the left atrium, left ventricle, and aorta without opacification of the right ventricle and right ventricular outflow tract with injection into both hands suggested drainage of the upper part of the body into the left atrium. Thus, with the use of these contrast echocardiographic studies, we were able to arrive at the diagnosis of anomalous systemic venous connection to the left atrium before cardiac catheterisation and selective cineangiography. It could not be determined, however, whether an isolated right superior vena cava or persistent left superior vena cava alone was present or whether both were present.
ANOMALOUS SYSTEMIC VENOUS CONNECTION TO LEFT ATRIUM

Although anomalous systemic venous connection to the left atrium in association with other congenital heart defects ${ }^{16} 17$ or with asplenia-polysplenia syndromes ${ }^{18} 19$ is well documented, it is rare as an isolated anomaly. To our knowledge, there are only four reported cases of isolated anomalous connection of the right superior vena cava to the left atrium. ${ }^{20-23}$ The case reported in this paper is the fifth case of isolated right superior vena cava connection to left atrium. The pertinent features of these five cases are given in Table 2 . All but one were children at the time of first presentation with symptoms. The lone exception was a 34-year-old woman reported by Park et al. ${ }^{23}$ All cases including ours were female and, therefore, it is tempting to postulate a definite sex predilection for this anomaly We hasten, however, to add that this apparent sex predilection is probably related to the small number of cases reported and is a rare coincidence. The presenting symptom was cyanosis in all patients, with exertional dyspnoea in two. Physical examination with the exception of cyanosis was by and large normal. Neck vein distension was noted in one case. ${ }^{22}$ This finding may be attributed to severe dilatation of the superior vena cava observed by angiography and at operation. But the cause of the dilatation was not determined. ${ }^{22}$

Chest $x$-rays were normal, as were electrocardiograms except for one case in which the electrocardiogram was interpreted as left ventricular

Table 2 Summary of reported cases of right superior vena cava to left atrium

\begin{tabular}{|c|c|c|c|c|c|c|c|}
\hline Author & $\begin{array}{l}\text { Age (y) } \\
\text { and sex }\end{array}$ & $\begin{array}{l}\text { Presenting } \\
\text { symptoms }\end{array}$ & $\begin{array}{l}\text { Physical } \\
\text { examination }\end{array}$ & $\mathrm{X}-r a y$ & $\begin{array}{l}\text { Electrocardio- } \\
\text { gram }\end{array}$ & Diagnosis & Surgery \\
\hline Wood $^{20}$ & $10, F$ & $\begin{array}{l}\text { Cyanosis and } \\
\text { exercise } \\
\text { intolerance }\end{array}$ & $\begin{array}{l}\text { Single 2nd } \\
\text { sound }\end{array}$ & Normal & LVH* $^{\star}$ & Angiography & $\begin{array}{l}\text { Not } \\
\text { recommended }\end{array}$ \\
\hline Kirsh et al..$^{21}$ & $2, F$ & Cyanosis & Clubbing & $\begin{array}{l}\text { ? RV } \\
\text { hypoplasia }\end{array}$ & Normal & $\begin{array}{l}\text { Angiography } \\
\text { and surgery }\end{array}$ & $\begin{array}{l}\text { Successful } \\
\text { correction }\end{array}$ \\
\hline Braudo et al. ${ }^{22}$ & 3, F & $\begin{array}{l}\text { Cyanosis and } \\
\text { growth } \\
\text { retardation }\end{array}$ & $\begin{array}{l}\text { Clubbing, neck } \\
\text { vein distension, } \\
\text { ejection click, } \\
\text { and murmur }\end{array}$ & Normal & Normal & $\begin{array}{l}\text { Angiography } \\
\text { and surgery }\end{array}$ & $\begin{array}{l}\text { Successful } \\
\text { correction }\end{array}$ \\
\hline Park et al. ${ }^{33}$ & $34, F$ & $\begin{array}{l}\text { Cyanosis and } \\
\text { dyspnoea on } \\
\text { exertion }\end{array}$ & Normal & Normal & $\begin{array}{l}\text { Non-specific, } \\
\text { ST, T wave } \\
\text { changes }\end{array}$ & Angiography & $\begin{array}{c}\text { Refused by } \\
\text { patient }\end{array}$ \\
\hline Present case & $8 / 12, F$ & Cyanosis & Normal & Normal & Normal & Angiography & $\begin{array}{l}\text { Awaiting } \\
\text { surgery }\end{array}$ \\
\hline
\end{tabular}

$\star$ See the text.

LVH, left ventricular hypertrophy; RV, right ventricle. 
hypertrophy. ${ }^{20}$ The voltage criteria used, ${ }^{20}$ however, would not meet the current criteria. ${ }^{24}$ Moderate degrees of polycythaemia and arterial unsaturation were present in cases in which these data were reported. Diagnosis was made by angiography in all and in two cases 2122 the diagnosis was also substantiated at operation. The role of contrast echocardiography in the diagnosis of this anomaly need not be re-emphasised and indeed it was the major purpose for reporting this case. Nuclear angiography would also be helpful in delineating these anomalies. ${ }^{23}$ Though cardiac catheterisation and angiography remain the most useful procedures to confirm the diagnosis, they are not without hazard; use of these anomalous venous channels for catheterisation has been reported to produce paroxysmal supraventricular tachycardia, occasional angina, shock, and cardiac arrest. ${ }^{25} 26$

The cases reported by Kirsh et al. ${ }^{21}$ and Braudo et $a l .{ }^{22}$ had successful surgical correction. Operation was refused by the patient described by Park and associates ${ }^{23}$ and it was not recommended in Wood's case. ${ }^{20}$

A 15-year-old child was reported by Tuchman et al. ${ }^{27}$ in whom the superior vena cava entered the left atrium. This was first diagnosed by cardiac catheterisation with subsequent confirmation at necropsy. It was not clear, however, from the description whether it was a left or right superior vena cava. ${ }^{23}$ Other types of "isolated" anomalous systemic venous connections to the left atrium are also rare and include persistent left superior vena cava into the left atrium, ${ }^{16}{ }^{28-33}$ inferior vena cava into the left atrium, ${ }^{15}{ }^{34-36}$ and total anomalous systemic venous drainage into the left atrium. ${ }^{37}$

\section{EMBRYOLOGICAL ORIGIN}

In an attempt to explain the origin of the right superior vena cava to left atrium, persistence of the cephalic portion of the right valve of the sinus venosus ${ }^{22}$ and leftward and cephalic displacement of the right horn of sinus venosus ${ }^{21}{ }^{23}$ have been postulated. Misplaced interatrial septum as a cause for this anomaly was mentioned ${ }^{21} 22$ but was excluded on the basis that the orifice of the inferior vena cava and coronary sinus would also be located on the left atrial side of the septum if this occurred. ${ }^{21}{ }^{22}$ More than normal leftward or cephalic displacement of the sinus venosus postulated by Kirsh and associates ${ }^{21}$ may not produce this anomaly unless associated with a shift of the embryological interatrial septae (septum spurium, primum, and secundum) to the right of (or caudal to) the common cardial vein. Persistence of the cephalic portion of the right valve of the sinus venosus as suggested by
Braudo et al.$^{22}$ may not be tenable because this would also result in the entrance of the inferior vena cava and even the coronary sinus into the left atrium.

An orderly sequence of events with precise timing is necessary for normal development of the cardiac structures. If, for some reason, the sinus venosus becomes incorporated into the right atrium sooner than normal or if the right horn of the sinus venosus grows in a vertical direction (with resultant increase in relative distance between the superior and inferior vena cava) earlier than normal, the cephalic continuation of the venous valves, the septum spurium, and thereafter the septum primum and secondum may come to lie on the right of (or caudal to) the superior vena cava and thereby result in right superior vena cava to left atrium. Alternatively, later than normal timing of development of venous valves and septum spurium (septum primum and secundum to follow) may similarly result in the above-described phenomenon. Though this hypothesis may appear reasonable on theoretical grounds, no evidence to support this hypothesis could be provided from the reported cases.

The authors thank Drs W Covitz, P Gilman, W Strong, and J Wilkins for their contribution in the preparation of this report.

\section{References}

1 Gramiak R, Shah PM. Echocardiography of the aortic root. Invest Radiol 1968; 3: 356-66.

2 Gramiak R, Shah PM, Kramer DH. Ultrasound cardiography: contrast studies in anatomy and function. Radiology 1969; 92: 939-48.

3 Feigenbaum H, Stone JM, Lee DA, Nasser WK, Chang S. Identification of ultrasound echoes from the left ventricle by use of intracardiac injections of indocyanine green. Circulation 1970; 41: 615-21.

4 Pieroni D, Varghese PJ, Rowe RD. Echocardiography to detect shunt and valvular incompetence in infants and children (abstract). Circulation 1973; 48, suppl IV: 81.

5 Kerber RE, Kloschos JM, Lauer RM. Use of an ultrasonic contrast method in the diagnosis of valvular regurgitation and intracardiac shunts. $\mathrm{Am}$ f Cardiol 1974; 34: 722-7.

6 Valdes-Cruz LM, Pieroni DR, Roland JMA, Varghese PJ. Echocardiographic detection of intracardiac right-to-left shunts following peripheral vein injections. Circulation 1976; 54: 558-62.

7 Valdes-Cruz LM, Pieroni DR, Roland JMA, Shematek JP. Recognition of residual postoperative shunts by contrast echocardiographic techniques. Circulation 1977; 55: 148-52.

8 Duff DF, Gutgesell HP. The use of saline for ultrasonic detection of right-to-left shunt in postoperative period (abstract). Am $\mathcal{F}$ Cardiol 1976; 37: 132. 
9 Seward JB, Tajik AJ, Hagler D, Ritter PG. Peripheral venous contrast echocardiography. $A m \mathcal{F}$ Cardiol 1977; 39: 202-12.

10 Seward JB, Tajik AJ, Spangler JG, Ritter DG. Echocardiographic contrast studies. Initial experience. Mayo Clin Proc 1975; 50: 163-92.

11 Seward JB, Tajik AJ, Hagler DJ, Ritter DG. Contrast echocardiography in single or common ventricle. Circulation 1977; 55: 513-9.

12 Serwer GA, Armstrong BE, Anderson PAW, Sherman D, Benson DW Jr, Edwards SB. Use of contrast echocardiography for evaluation of right ventricular hemodynamics in the presence of ventricular septal defects. Circulation 1978; 58: 327-36.

13 Meyer RA. Pediatric echocardiography. Philadelphia: Lea \& Febiger, 1977: 57-92.

14 Rees AH, Rao PS, Rigby JJ, Miller MD. Echocardiographic estimation of a left-to-right shunt in isolated ventricular septal defects. Eur $\mathcal{F}$ Cardiol 1978; 7: 25-33.

15 Meadows WR, Bergstrand I, Sharp JT. Isolated anomalous connection of a great vein to the left atrium: the syndrome of cyanosis and clubbing "normal" heart, and left ventricular hypertrophy, on electrocardiogram. Circulation 1961; 24: 669-76,

16 Friedlich A, Bing RJ, Blount SG Jr. Physiological studies in congenital heart disease: IX Circulatory dynamics in the anomalies of venous return to the heart including pulmonary arteriovenous fistula. Bull fohns Hopkins Hosp 1950; 86: 20-57.

17 Winter FS. Persistent left superior vena cava: survey of world literature and report of thirty additional cases. Angiology 1954; 5: 90-132.

18 Raghib G, Ruttenberg HD, Anderson RC, Amplatz $\mathrm{K}$, Adams $\mathrm{P} \mathrm{Jr}$, Edwards JE. Termination of left superior vena cava in left atrium, atrial septal defect and absence of coronary sinus: a developmental complex. Circulation 1965; 31: 906-18.

19 Rao PS, Leonard T. Polysplenia syndrome. Cardiol Digest 1976; 11: 14-22 (March).

20 Wood P. Diseases of the heart and circulation. 2nd ed. London: Eyre \& Spottiswood, 1956: 457-8.

21 Kirsch WM, Carlsson E, Hartmann AF Jr. A case of anomalous drainage of the superior vena cava into the left atrium. $\mathcal{F}$ Thorac Cardiovasc Surg 1961; 41: 550-6.

22 Braudo M, Beanlands DS, Trusler G. Anomalous drainage of the right superior vena cava into the left atrium. Can Med Assoc f 1968; 99: 715-9.

23 Park HM, Smith ET, Silberstein EB. Isolated right superior vena cava draining into left atrium diagnosed by radionuclide angiocardiography. $f \mathrm{Fucl} \mathrm{Med}$ $1974 ; 14: 240-2$.

24 Liebman J, Plonsey R. Electrocardiography. In:
Moss AJ, Adams FH, Emmanouilides GC, eds. Heart disease in infants, children and adolescents. 2nd ed. Baltimore: Williams \& Wilkins, 1977: 18-61.

25 Rao PS, Molthan ME. Systemic venous anomalies and partial heterotaxia with normal heart. $A m \mathcal{F} D i s$ Child 1973; 125: 749-52.

26 Rowe RD: Anomalies of venous return. In: Keith JD, Rowe RD, Vlad P, eds. Heart disease in infancy and childhood. 3rd ed. New York: Macmillan, 1978: 554-88.

27 Tuchman H, Brown JF, Huston JH, Weinstein AB, Rowe GG, Crumpton $C W$. Superior vena cava draining into left atrium: another cause for left ventricular hypertrophy with cyanotic congenital heart disease. $A m \mathcal{F}$ Med 1956; 21 : 481-4.

28 Ödman P. A persistent left superior vena cava communicating with the left atrium and pulmonary vein. Acta Radiol 1953; 40: 554-60.

29 Davis WH, Jordaan FR, Snyman HW. Persistent left superior vena cava draining into the left atrium as an isolated anomaly. Am Heart f 1959; 57: 616-22.

30 Fraser RS, Dvorkin J, Rossall RE, Eidem R. Left superior vena cava. A review of associated congenital heart lesions, catheterization data and roentgenologic findings. $A m \mathcal{F}$ Med 1961; 31: 711-6.

31 Meadows WR, Sharp JT. Persistent left superior vena cava draining into the left atrium without arterial oxygen unsaturation. Am f Cardiol 1965; 16: 273-9.

32 Taybi H, Kurlander GJ, Lurie PR, Campbell JA. Anomalous systemic venous connection to the left atrium or to a pulmonary vein. Am $\mathcal{f}$ Roentgenol 1965; 94: 62-77.

33 Sherafat M, Friedman S, Waldhausen JA. Persistent left superior vena cava draining into the left atrium with absent right superior vena cava. Ann Thorac Surg 1971; 11: 160-4.

34 Gardner DL, Cole L. Long survival with inferior vena cava draining into left atrium. Br Heart $\mathcal{f}$ 1955; 17: 93-7.

35 Gautam HP. Left atrial inferior vena cava with atrial septal defect. $\mathcal{F}$ Thorac Cardiovasc Surg 1968; 55: 827-29.

36 Kim YS, Serratto M, Long DM, Hastreiter AR. Left atrial inferior vena cava with atrial septal defect. Ann Thorac Surg 1971; 11: 165-70.

37 Viart P, LeClerc JL, Primo G, Polis O. Total anomalous systemic venous drainage. $A m \mathcal{F}$ Dis Child $1977 ; 131$ : 195-8.

Requests for reprints to Professor P Syamasundar Rao, Department of Pediatrics, Medical College of Georgia, Augusta, Georgia, 30912, USA. 